\title{
Thinking strategically for COVID-19: suppress and lift, to flatten or to crush?
}

\author{
Jade Khalife ${ }^{1}$ \\ 'Lund University, Malmö, Sweden (Correspondence to: Jade Khalife: jade.khalife@med.lu.se).
}

Citation: Khalife J. Thinking strategically for COVID-19: suppress and lift, to flatten or to crush? East Mediterr Health J. 2020;26(8):877-878. https://doi. org/10.26719/emhj.20.091

Received: 13/05/20; accepted: 06/07/20

Copyright (c) World Health Organization (WHO) 2020. Open Access. Some rights reserved. This work is available under the CC BY-NC-SA 3.0 IGO license (https://creativecommons.org/licenses/by-nc-sa/3.o/igo).

A perfect strategy to tackle COVID-19 does not exist, but it is timely for countries to consider an endgame. This includes moving on from a mindset of immediate response towards a long-term strategy, necessarily updated with the developing evidence. The chaotic response and squandering of time seen in several countries throughout February and March 2020 should not be repeated.

Most countries are currently engaged in phases of containment, mitigation, or a combination of both. 'Flattening the curve' has been widely adopted to help delay the epidemic curve peak and allow health-care systems to cope with demand (1). Recent modelling suggests that a strategy of suppression $\left(R_{t}<1\right)$, rather than mitigation $\left(R_{t}>1\right)$, would save the most lives and avoid exceeding healthcare capacity $(2,3)$. Beyond modelling limitations, this was also demonstrated in Wuhan, China, which witnessed the first successful suppression of widespread COVID-19 (4). By the end of February 2020, the suppression measures in Wuhan had driven the COVID-19 reproductive number $\left(R_{t}\right)$ to 0.3 (4). Such strong suppression measures result in 'crushing the curve' within a matter of weeks, as the decline would be exponential (5).

Whether pursuing curve flattening or crushing, many countries with widespread cases have resorted to lockdowns, alongside physical distancing and other measures. However, lockdowns cannot be maintained indefinitely, and stepwise lifting is underway in several countries. A common mistake has been to assume a second wave similar to the first would occur when lockdowns are lifted (2). This ignores the impact of maintained individual and country-level measures, which were largely absent during the first wave (6). The question then arises of how this will play in the longer term, at least until a vaccine is available.

A 'suppress and lift' approach is being formally advanced, particularly in Hong Kong and Singapore (7). Interestingly, other countries may be drifting to such an approach as well, albeit implicitly. Those lifting from lockdowns and closures, but acknowledging possible resumption or other measures in the event of surges, are following 'suppress and lift'. Typically, this approach involves cyclic implementation of restrictions to suppress transmission, and lifting restrictions once at a desired or acceptable level (7). What is an 'acceptable' level will vary across and possibly within countries, in terms of new cases or deaths. Trade-offs are often unavoidable, particularly considering human health and well-being, employment and economy.

A 'crushing the curve' scenariowould have suppression drive the disease to low levels (near-zero), thus 'resetting' countries from mitigation to containment, and lifting for several weeks or a few months. This would last until a threshold level is exceeded, prompting the next suppress and lift cycle. By June 2020 several countries had succeeded in crushing the curve, including low and middle-income countries such as Cambodia, Cyprus, Latvia, Slovakia, Slovenia, Thailand, Tunisia and Viet Nam, as well as Australia, Iceland and New Zealand.

A 'flatten the curve' scenario would primarily differ in having a more modest suppression (by intensity or temporally), to maintain new cases to within healthcare capacities. This has been underway most notably in the Netherlands, Sweden, the United Kingdom and the United States of America. Which of these two scenarios is desirable deserves greater discussion, particularly considering the large difference in potential lives saved and the 'normalcy' of inter-cyclic periods.

The crisis expectedly places considerable burden on the physical and mental well-being of most individuals, as well as their ability to engage in society for leisure and for work. This is greater for the most vulnerable, including children, the elderly and persons with mental and physical challenges, and lower socioeconomic groups. The expanded capacity of health-care systems for COVID-19 also means decreased access to health care for many 'regular' conditions; this cannot endure and increasing overall health-care capacity would be limited.

A reversal of the chronic under-funding of health systems is one of the major changes that would be sought following this crisis. This goes alongside addressing the unequitable and unsustainable frameworks within which human societies function. Much will be learned from the early experiences of countries currently pioneering suppress and lift, including how to tailor more targeted and effective measures. Beyond vaccination, a combination of factors will remain necessary to keep COVID-19 at bay, including better treatment, enhanced surveillance and monitoring, rapid response mechanisms, and active community participation. 
An active surveillance and response system has a crucial role to play in any strategy to counter COVID-19. With increasing recognition of the challenges posed by super-spreading events and asymptomatic/presymptomatic infection, developing the approaches and capacities to test, track and trace the disease are an urgent priority. Without such systems in place, even countries with low COVID-19 levels would be unable to long maintain their status.

Many countries owe much of their success in suppressing the outbreak to communities encouraging volunteering and compliance with measures.
Communities can also play a central role in identifying gaps and in developing new ideas and solutions. A national strategy would empower community participation and leadership, be responsive to their needs and provide clarity on the rationale, milestones and destination (8).

It is timely for populations and governments to engage in thinking strategically towards an endgame for COVID-19. A clear strategy encourages people to think outside of the box and develop new ways to cope and even thrive while countering COVID-19. Unlocking the full potential of humanity to participate in this requires nothing less.

\section{References}

1. World Health Organization. WHO Director-General's opening remarks at the media briefing on COVID-19-18 March 2020 2020 (https://www.who.int/dg/speeches/detail/who-director-general-s-opening-remarks-at-the-media-briefing-on-covid-19---18march-2020, accessed 15 April 2020).

2. Ferguson NM, Laydon D, Nedjati-Gilani G, Imai N, Ainslie K, Baguelin M, et al. Impact of non-pharmaceutical interventions (NPIs) to reduce COVID-19 mortality and healthcare demand. London: Imperial College COVID-19 Response Team; 2020 doi: $10.25561 / 77482$

3. Walker PG, Whittaker C, Watson O, Baguelin M, Ainslie KEC, Bhatia S, et al. The Global Impact of COVID-19 and Strategies for Mitigation and Suppression. London: Imperial College COVID-19 Response Team; 2020 doi: 10.25561/77735

4. Pan A, Liu L, Wang C, Guo H, Hao X, Wang Q, et al. Association of public health interventions with the epidemiology of the COVID-19 outbreak in Wuhan, China. JAMA 2020;323(19):1915-23. doi: 10.1001/jama.2020.6130

5. Shen C, Bar-Yam Y. Pandemic math: Stopping outbreaks. New England Complex Systems Institute 202017 February (https:// necsi.edu/pandemic-math).

6. Shen C, Taleb N, Bar-Yam Y. Review of Ferguson NM, Laydon D, Nedjati-Gilani G, Imai N, Ainslie K, Baguelin M, et al. Impact of non-pharmaceutical interventions (NPIs) to reduce COVID-19 mortality and healthcare demand. New England Complex Systems Institute 202021 March. (https://necsi.edu/review-of-ferguson-et-al-impact-of-nonpharmaceutical-interventions-version-2).

7. Leung G. Lockdown can't last forever. Here's how to lift it. The New York Times 6 April, 2020 (https://www.nytimes. com/2020/04/06/opinion/coronavirus-end-social-distancing.html).

8. UNAIDS. Rights in the time of COVID-19: Lessons from HIV for an effective, community-led response, 2020 (https://www. unaids.org/en/resources/documents/2020/human-rights-and-covid-19). 